\title{
Pengaruh Arah Serat Carbon Fiber Reinforced Polymer Terhadap Kuat Tekan Beton Normal Menggunakan Material Lokal Pasir Samboja di Wilayah Kalimantan Timur
}

\author{
Sara Wibawaning Respati ${ }^{1 *}$, Karmila Achmad ${ }^{2}$. \\ $1^{*}, 2$ Jurusan Teknik Sipil - Politeknik Negeri Balikpapan \\ milabpp@yahoo.co.id
}

\begin{abstract}
The necessity of the high strength concrete will appear in the future in many big construction projects in Balikpapan. This condition is not supported by the cost to send the material from other places. Local material, Samboja sand, is proved that it has a high strength [1]. CFRP was implemented as a core concrete reinforcement and to hold up cracking, furthermore, as an external confinement, CFRP is also able to increase concrete strength by $61.18 \%$ [2]. However, the application of difference fiber trajectory has not been studied. This research aims to get the concrete strength of the concrete that use local material Samboja Sand, and CFRP as external confinement with variation of its width and trajectory. There were 6 variations and 27 samples used in this research. The result of this study is that the effect of CFRP width for each of the fiber direction compared to normal concrete are -2,57\%, $3,71 \%, 6,86 \%, 13,14 \%, 20,48 \%$, and $26,76 \%$ for the V2, V3, V5, H2, H3, and $\mathrm{H} 5$ samples respectively.
\end{abstract}

Keywords: Fiber Trajectory, CFRP, Samboja Sand, Fiber Width

\begin{abstract}
Abstrak
Kebutuhan beton dengan kuat tekan yang lebih tinggi timbul di masa yang akan datang pada proyek-proyek besar di Balikpapan. Hal ini kurang didukung karena tingginya biaya yang akan dibutuhkan untuk mendatangkan material dari luar daerah. Material lokal pasir samboja terbukti memiliki kekuatan yang tinggi [1]. Untuk perkuatan digunakan CFRP, selain berfungsi sebagai pengekang inti beton dan menunda keretakan, perkuatan ekternal, CFRP juga mampu meningkatkan kuat tekan beton normal sebesar 61,18\% [2]. Namun dalam aplikasinya arah utama serat CFRP terkadang tidak menjadi perhatian utama. Penelitian ini bertujuan untuk mendapatkan kuat tekan beton material local pasir Samboja dengan perkuatan eksternal CFRP variasi tebal dan arah serat. Ada 3 kelompok benda uji dengan 6 variasi dan 27 benda uji yang digunakan dalam penelitian ini. Dari hasil pengujian diperoleh pengaruh tebal CFRP pada masing-masing arah serat terhadap kuat tekan beton normal berturut-turut adalah -2,57\%, 3,71\%, $6,86 \%, 13,14 \%, 20,48 \%, 26,76 \%$, dan masing-masing untuk benda uji V2, V3, V5, H2, H3, dan H5.
\end{abstract}

Kata kunci: Arah Serat, CFRP, Pasir Samboja, Tebal Serat

\section{Pendahuluan}

Selain maraknya pembangunan, beberapa bangunan yang ada juga tidak menutup kemungkinan berubah fungsi sehingga dibutuhkan perkuatan terhadap konstruksi yang ada. Perkuatan struktur bertujuan untuk mengembalikan atau meningkatkan kekuatan elemen struktur agar mampu menahan beban sesuai dengan rencana. Umumnya perkuatan yang dilakukan pada struktur adalah perkuatan eksternal. Salah satu material yang digunakan untuk perkuatan ekternal adalah CFRP. Selain berfungsi sebagai pengekang inti beton dan menunda keretakan, perkuatan ekternal CFRP juga mampu meningkatkan kuat tekan beton normal sebesar 61,18\% [2]. Namun dalam aplikasinya arah utama serat CFRP terkadang tidak menjadi perhatian utama. Bagaimanapun juga tentu arah serat utama CFRP dalam aplikasinya akan memberikan pengaruh terhadap kekuatan tekan beton. 
Sehingga perlu dilakukan penelitian Pengaruh arah serat Carbon Fiber Reinforced Polymer (CFRP) terhadap kuat tekan beton normal menggunakan material local pasir Samboja di wilayah Kalimantan Timur

\subsection{Fiber Reinforced Polymer (FRP)}

Fiber Reinforced Polymer (FRP) adalah inovasi perkuatan komposit yang saat ini banyak digunakan sebagai perkuatan eksternal tambahan pada struktur. FRP merupakan material komposit yang terdiri atas 3 bagian utama yaitu: fibers, polymers dan additive [3]. FRP memiliki kekuatan tinggi (Carbon, Glass dan Aramid) yang ada dalam resin polimer (polyester, vinylester atau epoxy) dan filler (kaolin clay, calcium carbonate dan alumina).

\subsection{Carbon Reinforced Fiber Polymer (CFRP)}

Carbon fiber atau serat carbon merupakan serat yang mengandung setidaknya $90 \%$ berat karbon. Umumnya serat carbon yang digunakan adalah fiber graphite yang merupakan serat dengan kandungan karbon diatas $95 \%$ beratnya dengan jenis poliakrilonitril (PAN), (petroleum) minyak bumi, serat selulosa (Viscose rayon, katun) dan fiber phenolic tertentu [3]. Serat karbon cocok untuk aplikasi yang harus memenuhi persyaratan kekuatan, kekakuan, ringan dan ketahanan terhadap fatigue [3]. Tidak seperti serat glass dan aramid, serat carbon tidak korosi atau pecah pada suhu kamar. Selain itu karbon juga dapat digunakan dalam aplikasi yang memerlukan ketahanan suhu tinggi, kelembaman dan redaman [3].

\section{Metoda Penelitian}

\subsection{Tempat Penelitian}

Penelitian ini dilakukan di Laboratorium Beton Jurusan Teknik Sipil Politeknik Negeri Balikpapan.

\subsection{Rancangan Penelitian}

Benda uji dibuat berdasarkan hasil mix design yang mengacu pada SNI 03-2834-2000 tentang tata cara pembuatan rencana campuran beton normal [4]. Benda uji yang digunakan dalam penelitian ini silinder sebanyak 27 benda uji dengan 9 variasi, yang dibagi dalam 3 kelompok dengan rincian sebagai berikut:

Tabel 1. Rincian Benda Uji

\begin{tabular}{|c|c|c|c|c|}
\hline $\begin{array}{l}\text { Kelompok } \\
\text { Benda Uji }\end{array}$ & $\begin{array}{c}\text { Jenis } \\
\text { variasi }\end{array}$ & $\begin{array}{c}\text { Waktu } \\
\text { Uji } \\
28 \\
\text { Hari }\end{array}$ & $\begin{array}{c}\text { Kode } \\
\text { Penamaan }\end{array}$ & Keterangan \\
\hline Original & $\begin{array}{l}\text { Beton } \\
\text { normal }\end{array}$ & 3 & $\begin{array}{l}\text { BN1 - } \\
\text { BN3 }\end{array}$ & $\begin{array}{c}\text { Perbandingan } \\
\text { campuran } \\
\text { mengikuti } \\
\text { standar } \\
\text { SKSNI } \\
\end{array}$ \\
\hline \multirow{4}{*}{$\begin{array}{l}\text { Arah serat } \\
\text { horisontal }\end{array}$} & $\begin{array}{l}\text { tebal } \\
\text { CFRP } \\
: 2 \mathrm{~cm} \\
\end{array}$ & 3 & $\mathrm{H} 21-\mathrm{H} 23$ & \multirow{4}{*}{$\begin{array}{c}\text { space : } 5 \mathrm{~cm} \\
\text { dan overlap } 5 \\
\mathrm{~cm}\end{array}$} \\
\hline & $\begin{array}{l}\text { tebal } \\
\text { CFRP } \\
: 3 \mathrm{~cm} \\
\end{array}$ & 3 & H31-H33 & \\
\hline & $\begin{array}{l}\text { tebal } \\
\text { CFRP } \\
: 5 \mathrm{~cm} \\
\end{array}$ & 3 & H51-H53 & \\
\hline & $\begin{array}{l}\text { Full } \\
\text { jacketi } \\
\text { ng } \\
\text { CFRP }\end{array}$ & 3 & HF1-HF3 & \\
\hline \multirow{4}{*}{$\begin{array}{l}\text { Arah serat } \\
\text { vertikal }\end{array}$} & $\begin{array}{l}\text { tebal } \\
\text { CFRP } \\
: 2 \mathrm{~cm} \\
\end{array}$ & 3 & V21-V23 & \multirow{4}{*}{$\begin{array}{c}\text { space : } 5 \mathrm{~cm} \\
\text { dan overlap } 5 \\
\mathrm{~cm}\end{array}$} \\
\hline & $\begin{array}{l}\text { tebal } \\
\text { CFRP } \\
: 3 \mathrm{~cm} \\
\end{array}$ & 3 & V31-V33 & \\
\hline & $\begin{array}{l}\text { tebal } \\
\text { CFRP } \\
: 5 \mathrm{~cm} \\
\end{array}$ & 3 & V51-V53 & \\
\hline & $\begin{array}{l}\text { Full } \\
\text { jacketi } \\
\text { ng } \\
\text { CFRP }\end{array}$ & 3 & VF1-VF3 & \\
\hline Total & enda uji & 27 & & \\
\hline
\end{tabular}

Keterangan kode penamaan benda uji :

- BN1-BN3: Benda uji beton normal untuk benda uji 1 sampai dengan benda uji 3 . Gambar 1.(a).

- H21-H23: Benda uji arah serat horisontal variasi tebal CFRP $2 \mathrm{~cm}$ untuk benda uji 1 sampai dengan benda uji 3. Gambar 1.(b).

- H31-H33: Benda uji arah serat horisontal variasi tebal CFRP $3 \mathrm{~cm}$ untuk benda uji 1 sampai dengan benda uji 3. Gambar 1.(c).

- H51-H53: Benda uji arah serat horisontal variasi tebal CFRP $5 \mathrm{~cm}$ untuk benda uji 1 sampai dengan benda uji 3. Gambar 1.(d). 
- HF1-HF3: Benda uji arah serat horisontal variasi tebal CFRP adalah full untuk benda uji 1 sampai dengan benda uji 3 . Gambar 1.(e).

- V21-V23: Benda uji arah serat vertikal variasi tebal CFRP $2 \mathrm{~cm}$ untuk benda uji 1 sampai dengan benda uji 3. Gambar 1.(f).

- V31-V33: Benda uji arah serat vertikal variasi tebal CFRP $3 \mathrm{~cm}$ untuk benda uji 1 sampai dengan benda uji 3. Gambar 1.(g).

- V51-V53: Benda uji arah serat vertikal

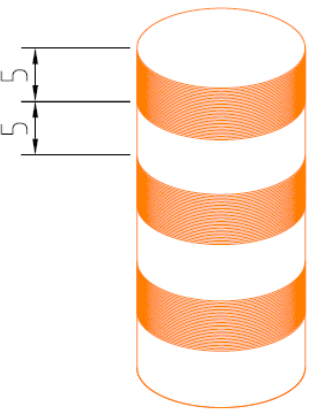

(d) $\mathrm{H} 5$ variasi tebal CFRP $5 \mathrm{~cm}$ untuk benda uji 1 sampai dengan benda uji 3. Gambar 1.(h).

- VF1-VF3: Benda uji arah serat vertikal variasi tebal CFRP adalah full untuk benda uji 1 sampai dengan benda uji 3 . Gambar 1.(i).

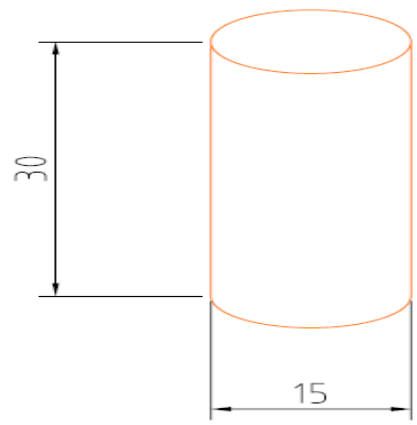

(a) $\mathrm{BN}$

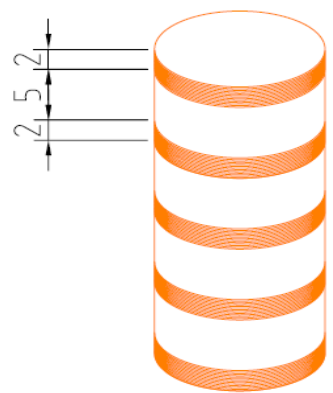

(b) $\mathrm{H} 2$
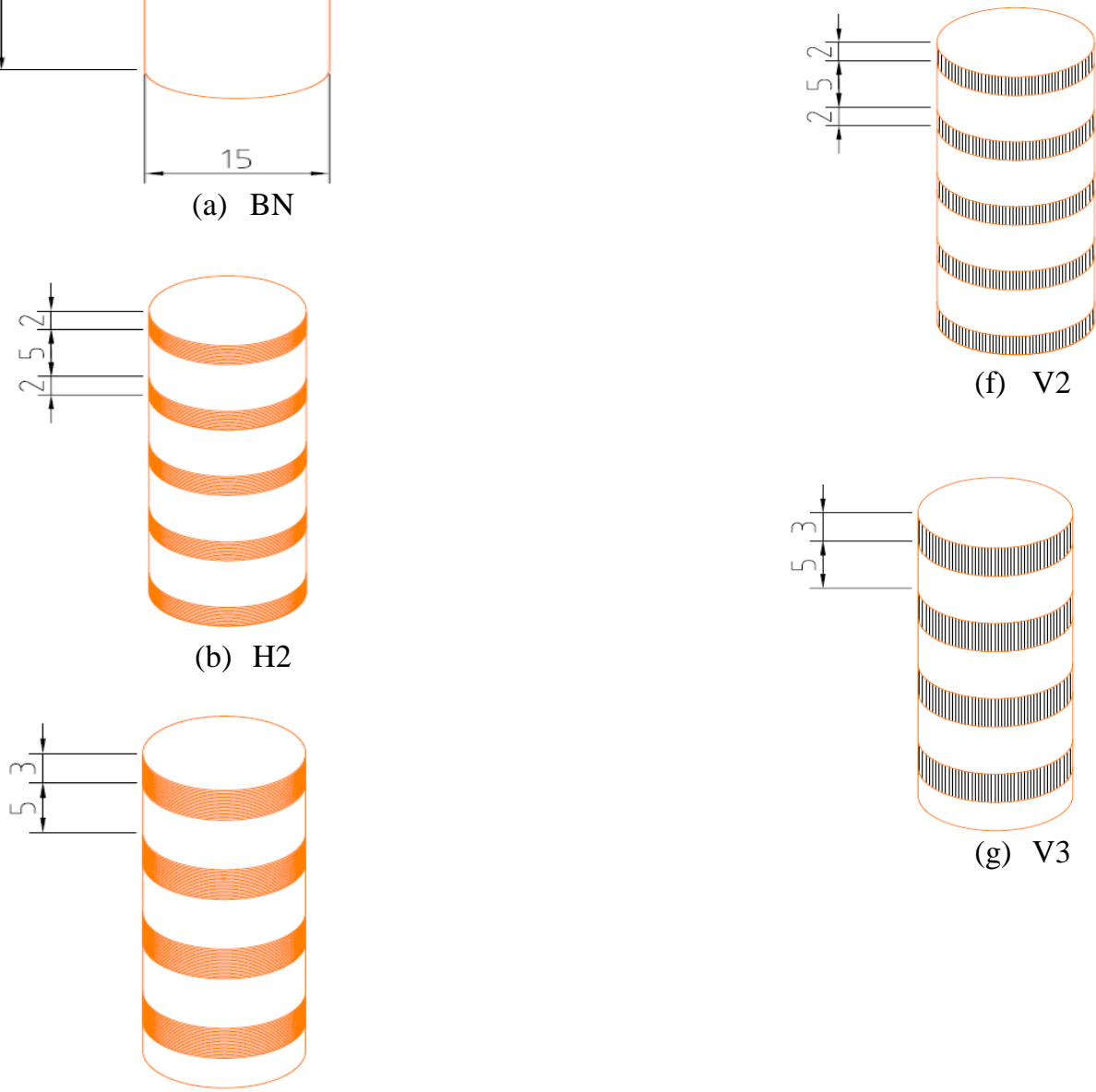

(f) V2

(c) $\mathrm{H} 3$

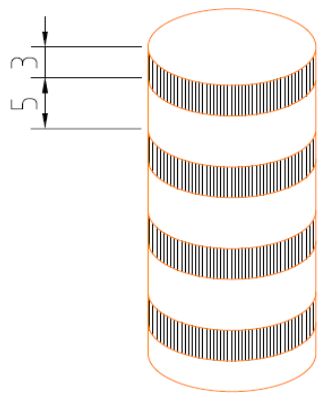

(g) V3 


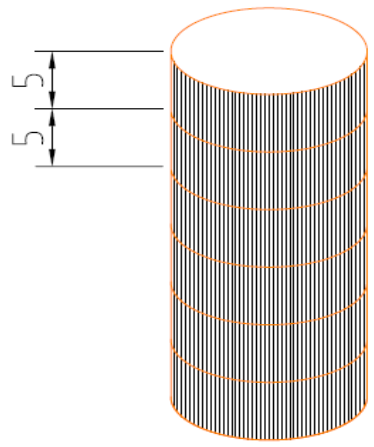

(h) V5

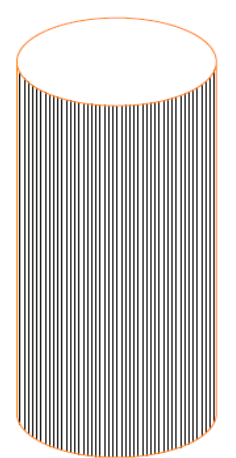

(i) $\mathrm{VF}$

Gambar 1. Rencana Benda Uji

\section{Hasil Penelitian}

\subsection{Hasil Pengujian Material Agregat Halus}

Dalam penelitian ini dilakukan pemeriksaan terhadap agregat halus berupa uji gradasi kehalusan butir, uji kadar air, uji berat jenis, uji berat isi dan uji kadar lumpur. Dari hasil pengujian gradasi kehalusan butir diperoleh nilai modulus halus butir sebesar 2,794 dan berada pada zona 4 [5]. Hasil pengujian kadar air menunjukan bahwa kadar air pasir samboja yang akan digunakan memenuhi syarat yaitu $4,86 \%<5 \%$. Berat jenis SSD pasir samboja adalah 2,12 dengan penyerapan sebesar $0,13 \%$. Berat isi 1,36 $\mathrm{gr} / \mathrm{cm} 3 \geq 1,2$ dan nilai kadar lumpur dari pengujian adalah $1,48 \%$ masih memenuhi syarat yaitu antara $1 \%$ s.d $5 \%$.

Dari keseluruhan pengujian terhadap material agregat halus pasir samboja memenuhi syarat pengujian sehingga material ini layak digunakan dalam campuran beton untuk benda uji silinder.

\subsection{Hasil Pengujian Material Agregat} Kasar

Dalam penelitian ini dilakukan pemeriksaan terhadap agregat halus berupa uji gradasi kehalusan butir, uji kadar air, uji berat jenis, uji berat isi dan uji kadar lumpur dan keausan. Dari hasil pengujian gradasi kehalusan butir diperoleh nilai modulus halus butir sebesar 7,771 dan berada pada zona 2 [5]. Hasil pengujian kadar air menunjukan bahwa kadar air kerikil palu yang akan digunakan memenuhi syarat yaitu $2,59 \%<5 \%$. Berat jenis SSD kerikil palu adalah 2,59 dengan penyerapan sebesar $0,002 \%$. Berat isi 1,86 dan nilai kadar lumpur dari pengujian adalah $0,44 \%$ serta nilai keausan kerikil palu adalah $20,6 \%$.

Dari keseluruhan pengujian terhadap material agregat karar karikil palu memenuhi syarat pengujian sehingga material ini layak digunakan dalam campuran beton untuk benda uji silinder.

\subsection{Uji Tekan Beton Umur 28 Hari}

Dari hasil uji tekan beton umur 28 hari maka diperoleh nilai kuat tekan beton terbesar adalah untuk benda uji dengan fully jacketing CFRP arah serat vertikal sebesar 21,89 $\mathrm{MPa}$ dan fully jacketing CFRP arah serat horizontal sebesar 25,48 MPa dengan peningkatan kuat tekan beton fully jacketing CFRP arah serat vertikal sebesar $21,52 \%$ dan fully jacketing CFRP arah serat horizontal sebesar 41,43\% terhadap beton normal BN. Secara rinci hasil kuat tekan beton dapat dilihat pada tabel 2 dan gambar 2 .

Terlihat pada tabel 2, bahwa nilai kuat tekan rata-rata beton umur 28 hari adalah $18,01 \mathrm{MPa} ; 17,55 \mathrm{MPa} ; 18,68 \mathrm{MPa} ; 19,25$ $\mathrm{MPa}$; 21,89 $\mathrm{MPa}$; 20,38 $\mathrm{MPa}$; 21,70 MPa; 22,84 $\mathrm{MPa}$ dan 41,43 $\mathrm{MPa}$ masing-masing untuk benda uji BN, V2, V3, V5, VF, H2, H3, H5 dan HF.

Dengan prosentase peningkatan kuat tekan terhadap beton normal pada umur beton 28 hari adalah $-2,57 \%$; 3,71\%; 6,86\%; $21,52 \% ; \quad 13,14 \% ; \quad 20,48 \%$; 26,76\% dan $41,43 \%$ masing-masing untuk benda uji V2, 
V3, V5, VF, H2, H3, H5 dan HF. Fuly jacketing CFRP dengan arah serat horizontal maupun arah serat vertikal terbukti mampu meningkatkan kuat tekan beton meskipun hasil arah serat vertikal tidank sebaik pemotongan dengan arah serat horizontal.

Tabel 2. Nilai Kuat Tekan Beton Umur 28 Hari

\begin{tabular}{|c|c|c|c|}
\hline \multirow[t]{2}{*}{ Benda Uji } & \multicolumn{3}{|c|}{ Umur 28 hari } \\
\hline & $\begin{array}{c}\mathrm{P} \\
(\mathrm{kN})\end{array}$ & $\begin{array}{c}\mathrm{f}^{\prime} \mathrm{c} \\
(\mathrm{Mpa})\end{array}$ & $\begin{array}{c}\text { Peningkatan kuat } \\
\text { tekan beton terhadap } \\
\text { BN }(\%)\end{array}$ \\
\hline BN1 & 230 & 14,80 & \\
\hline BN2 & 270 & 17,37 & \\
\hline $\mathrm{BN} 3$ & 340 & 21,87 & \\
\hline $\mathrm{BNtr}$ & 280 & 18,01 & \\
\hline V21 & 300 & 16,99 & \\
\hline V22 & 310 & 17,55 & \\
\hline V23 & 320 & 18,12 & \\
\hline V2tr & 310 & 17,55 & $-2,57$ \\
\hline V31 & 320 & 18,12 & \\
\hline V32 & 330 & 18,68 & \\
\hline V33 & 340 & 19,25 & \\
\hline V3tr & 330 & 18,68 & 3,71 \\
\hline V51 & 320 & 18,12 & \\
\hline V52 & 350 & 19,82 & \\
\hline V53 & 350 & 19,82 & \\
\hline $\mathrm{V} 5 \mathrm{tr}$ & 340 & 19,25 & 6,86 \\
\hline VF1 & 380 & 21,51 & \\
\hline VF2 & 380 & 21,51 & \\
\hline VF3 & 400 & 22,65 & \\
\hline VFtr & 387 & 21,89 & 21,52 \\
\hline $\mathrm{H} 21$ & 350 & 19,82 & \\
\hline $\mathrm{H} 22$ & 350 & 19,82 & \\
\hline $\mathrm{H} 23$ & 380 & 21,51 & \\
\hline $\mathrm{H} 2 \mathrm{tr}$ & 360 & 20,38 & 13,14 \\
\hline H31 & 360 & 20,38 & \\
\hline H32 & 390 & 22,08 & \\
\hline H33 & 400 & 22,65 & \\
\hline $\mathrm{H} 3 \mathrm{tr}$ & 383 & 21,70 & 20,48 \\
\hline H51 & 400 & 22,65 & \\
\hline H52 & 400 & 22,65 & \\
\hline H53 & 410 & 23,21 & \\
\hline $\mathrm{H} 5 \mathrm{tr}$ & 403 & 22,84 & 26,76 \\
\hline HF1 & 440 & 24,91 & \\
\hline HF2 & 450 & 25,48 & \\
\hline HF3 & 460 & 26,04 & \\
\hline HFtr & 450 & 25,48 & 41,43 \\
\hline
\end{tabular}

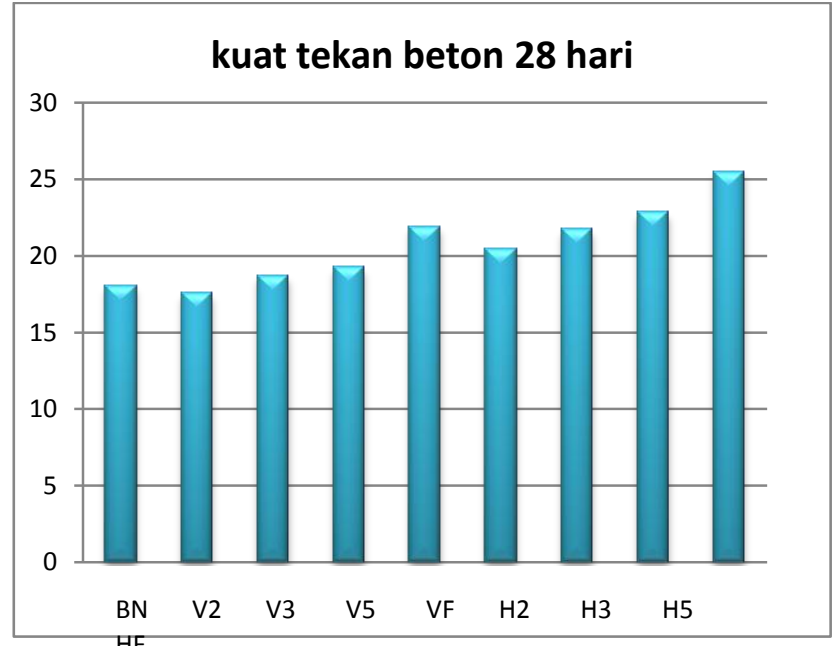

Gambar 2. Grafik Nilai Kuat Tekan Beton Umur 28 hari

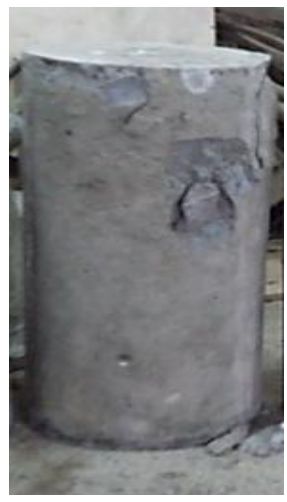

(a)

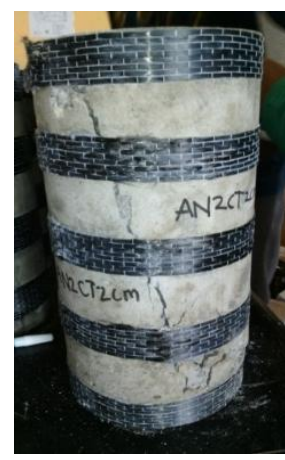

(b)

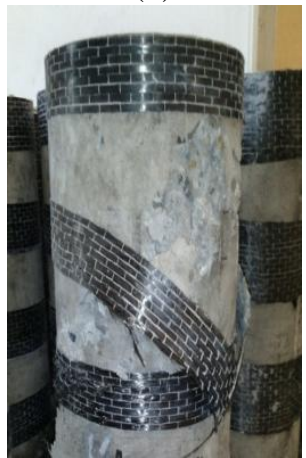

(c) 


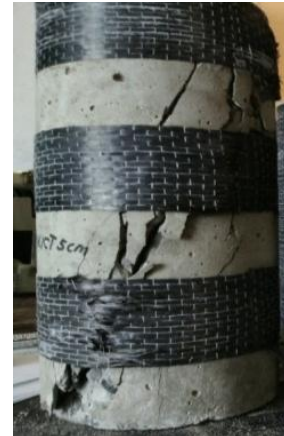

(d)

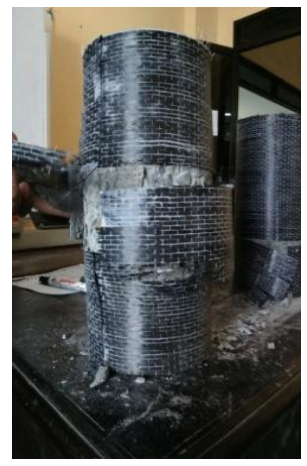

(e)

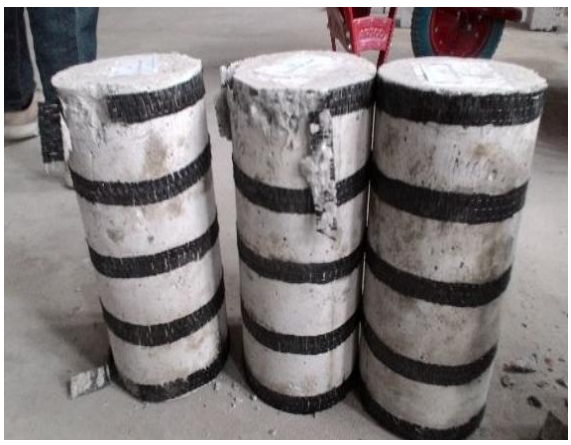

(f)

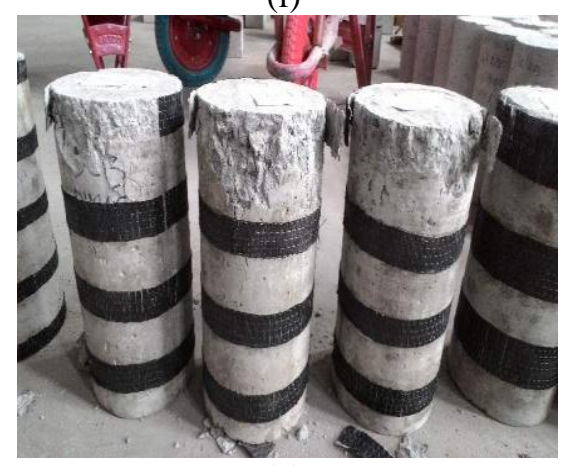

(g)

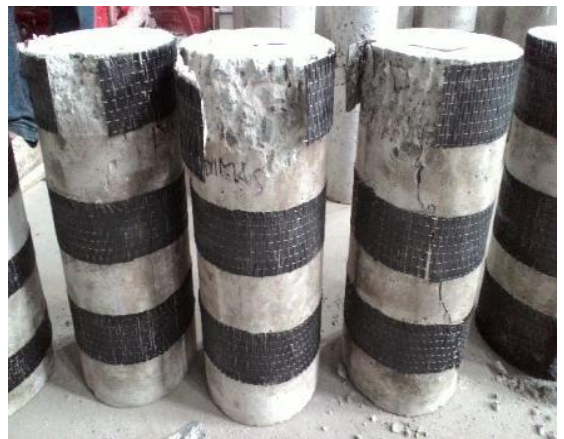

(h)

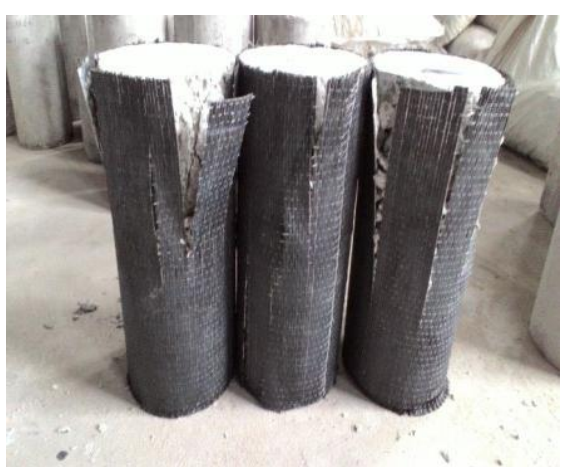

(i)

Gambar 3. Hasil Pengujian Umur 28 Hari : (a) BN, (b) V2, (c) V3, (d) V5, (e) VF, (f) H2, (g) H3, (h) H5 dan (i) $\mathrm{HF}$

Kerusakan beton normal umur 28 hari, dapat dilihat pada gambar 3.(a) berupa kerusakan pada cover beton sepanjang tinggi benda uji. Kerusakan yang terjadi pada V2 dapat dilihat pada gambar 3.(b) yaitu retak diagonal sepanjang tinggi silinder dan pada serat CFRP pada lapisan pertama dan kedua mulai terlihat putus. Pada benda uji V3 dapat dilihat pada gambar 3.(c), sambungan serat pada lapis kedua lepas dan terlihat kerusakan pada cover beton setengah tinggi silinder. Mirip dengan V2, kerusakan pada benda uji V5 dapat dilihat pada gambar 3.(d) berupa retak diagonal bahkan retak ini terlihat cukup besar membagi silinder menjadi 2 bagian. Namun benda uji masih bertahan karena ada CFRP yang menyelimutinya. Sampai dengan puncaknya saat serat-serat CFRP putus benda uji sudah tidak sanggup menahan beban tekan yang bekerja padanya. Hampir diseluruh sisi, terlihat warna putih pada serat CFRP yang menandakan CFRP berada pada batas putus serat. Kerusakan yang signifikan terjadi pada 
benda uji VF dapat dilihat pada gambar 3.(e), kegagalan benda uji ini diakibatkan oleh robeknya serat CFRP. Kegagalan diawali dengan putusnya serat CFRP dan mengakibatkan robeknya CFRP menjadi tiga bagian dan overlap hampir lepas. Pada bagian dalam benda uji terlihat bahwa beton dalam kondisi hancur.

Kerusakan yang terjadi pada $\mathrm{H} 2$ dapat dilihat pada gambar 3.(f) berupa putusnya serat CFRP. Berbeda dengan arah serat horizontal, maka pada serat vertikal CFRP lebih mudah putus karena serat yang tertahan hanya $2 \mathrm{~cm}$. Kerusakan yang terjadi pada $\mathrm{H} 3$ dapat dilihat pada gambar 3.(g) dan H5 pada gambar 3.(h), juga memiliki pola yang sama dengan $\mathrm{H} 2$ yaitu putusnya serat arah vertikal. Hanya pada benda uji H5 terjadi retak diagonal setinggi silinder beton. Kerusakan yang terjadi pada benda uji HF pada gambar 3.(i), serat CFRP robek searah vertikal dan robekan terjadi di beberapa sisi silinder. Dibagian dalam terlihat dengan jelas bahwa beton dalam keadaan hancur.

\section{Kesimpulan}

Dari hasil uji tekan umur beton 28 hari dalam penelitian ini maka kesimpulan yang bisa ditarik adalah:

1. Arah serat dalam aplikasi CFRP mempengaruhi nilai kuat tekan beton

2. Pengaruh tebal CFRP pada masingmasing arah serat terhadap kuat tekan beton normal berturut-turut adalah $2,57 \%, 3,71 \%, 6,86 \%, 13,14 \%, 20,48 \%$, $26,76 \%$, dan masing-masing untuk benda uji V2, V3, V5, H2, H3, dan H5.

3. Besar peningkatan kuat tekan yang terjadi akibat aplikasi arah serat vertikal dan arah serat horizontal adalah 18,01 MPa, 17,55 $\mathrm{MPa}, 18,68 \mathrm{MPa}, 19,25 \mathrm{MPa}, 21,89 \mathrm{MPa}$, 20,38 MPa, 21,70 MPa, 22,84 MPa, 25,48 $\mathrm{MPa}$ untuk benda uji BN, V2, V3, V5, VF, H2, H3, H5 dan HF.

4. Prosentase peningkatan kuat tekan beton fully jacketing CFRP arah serat vertikal adalah $21,52 \%$ dan fully jacketing CFRP arah serat horizontal sebesar $41,43 \%$.

\section{Saran}

Sehubungan dengan penelitian yang telah dilakukan terhadap beberapa saran yang dapat diberikan pada masa yang akan datang, saran-saran tersebut diantaranya :

1. Perlunya penambahan pengulangan benda uji dalam masing-masing variasi agar data yang diperoleh valid

2. Sebaiknya pemotongan CFRP arah serat vertikal dihindari karena membutuhkan material CFRP yang jauh lebih besar dibandingkan pemotongan horizontal.

3. Perlu penelitian lanjutan terkait optimalisasi biaya terhadap peningkatan kuat tekan dalam pembuatan benda uji untuk arah serat vertikal dan horizontal.

4. Perlu penelitian lanjutan terkait peningkatan kuat lentur balok untuk arah serat vertikal dan horizontal

5. Perlu penelitian lanjutan terkait alternative serat buatan lainnya untuk meningkatkan kuat tekan beton.

\section{Daftar Pustaka}

[1] Sunarno, "Penggunaan Pasir Samboja dan Kerikil dari Palu sebagai Bahan Pembuatan Beton Normal,'Jurnal Ilmiah Politeknik Balikpapan, vol. 4, no.1, pp. 15-20, 2012

[2] Sara WR, Karmila A, "Local Material Sand in East Kalimantan: Utilization with Fiber Reinforced Polymer Jacketing as an Effort to Increase the concrete Strength," Jurnal Teknologi Terpadu., vol. 3 no. 2, 2015

[3] Gangarao et al, Reinforced Concrete Design with FRP Composites. London: CRC Press, 2007.

[4] Badan Standardisasi Nasional. 2000. SNI 03-2834-2000 Tata Cara Pembuatan Rencana Campuran Beton Normal. Jakarta

[5] Mulyono, Tri. Teknologi Beton. Yogyakarta: Andi Offset, 2003. 